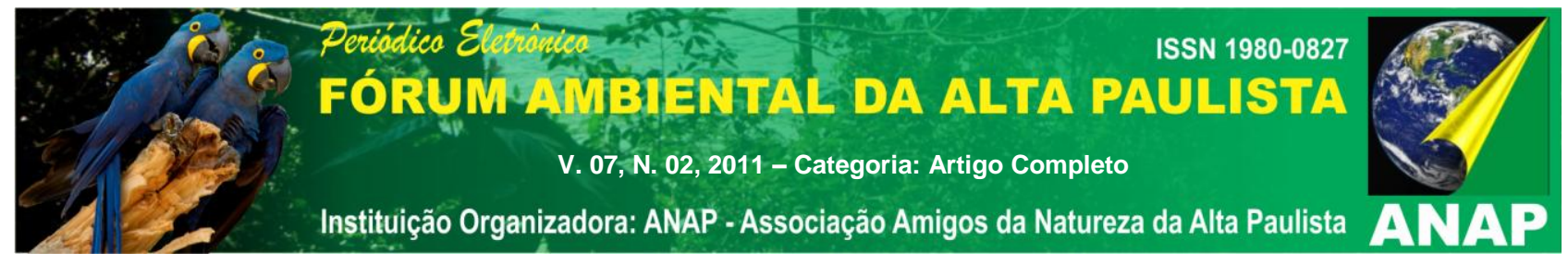

\title{
PLANEJAMENTO AMBIENTAL DA BACIA DO BALNEÁRIO DA AMIZADE NOS MUNICÍPIOS DE ÁLVARES MACHADO E PRESIDENTE PRUDENTE - SÃO PAULO
}

\section{Fernanda Bomfim Soares ${ }^{1}$}

\section{Antonio Cezar Leal ${ }^{2}$}

RESUMO: O presente artigo esta relacionado à pesquisa de iniciação científica inserida no Grupo de Pesquisa em Gestão Ambiental e Dinâmica Socioespacial (GADIS), da Faculdade de Ciências e Tecnologia, UNESP, campus de Presidente Prudente, e vincula-se a projetos mais amplos desenvolvidos com apoio da FAPESP, do CNPq e FEHIDRO. De modo geral, esses projetos possuem como objetivo principal analisar e contribuir para a efetivação de planejamentos ambientais de bacias hidrográficas e a formação de recursos humanos para atuação nos sistemas de gestão. Nesse contexto, o objetivo desta pesquisa é contribuir para o planejamento ambiental da bacia do Balneário da Amizade, como também para o gerenciamento de seus recursos hídricos, aprofundando conhecimentos teóricometodológicos sobre o tema. Os procedimentos metodológicos incluem revisão bibliográfica, elaboração do inventário ambiental, de modo a identificar as principais características e usos da terra na bacia hidrográfica do Balneário da Amizade, identificar os principais problemas ambientais, verificar e analisar as ações de gestão ambiental realizada nesta bacia por órgãos públicos e elaborar propostas de alteração de sua situação ambiental. O resultado final do trabalho será disponibilizado ao Comitê de Bacias Hidrográficas do Pontal do Paranapanema e às Prefeituras Municipais de Álvares Machado e Presidente Prudente.

PALAVRAS-CHAVE: Planejamento ambiental. Bacia hidrográfica. Balneário da Amizade.

\section{INTRODUÇÃO}

O processo de ocupação do Brasil caracterizou-se pela carência de planejamento que considerasse as potencialidades e fragilidades do ambiente, gerando muitos impactos ambientais e destruição de recursos naturais, 


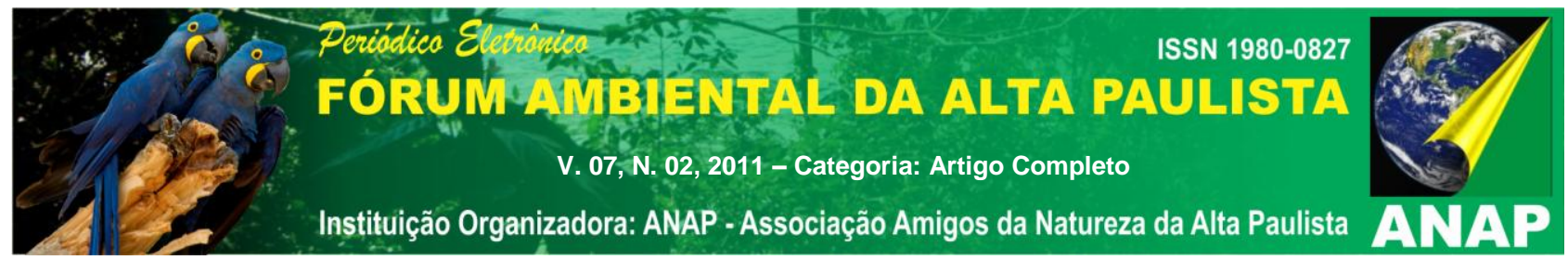

principalmente das florestas. Ao longo da história do País, a cobertura florestal nativa, representada pelos diferentes biomas, foi sendo fragmentada e cedendo espaço para as culturas agrícolas, as pastagens e as cidades. (ALMEIDA, 1999)

A noção de recursos naturais inesgotáveis e o modo de produção que impera no país estimularam e ainda estimulam a expansão da fronteira agrícola, ainda que se busque o aumento ou a manutenção da produtividade das áreas já cultivadas. Assim, o processo de fragmentação florestal foi intenso nas regiões economicamente mais desenvolvidas, o Sudeste e o Sul, e avança rapidamente para o Centro-Oeste e Norte, ficando a vegetação representada por florestas secundárias, em vários estados de degradação, salvo algumas reservas de florestas bem conservadas.

Da mesma forma, o crescimento urbano desordenado tem trazido efeitos bastante negativos para algumas áreas importantes das cidades, como pode ser observado particularmente nas bacias hidrográficas de mananciais destinados ao abastecimento público, como ocorre na bacia do Balneário da Amizade, gerando impactos ambientais que podem comprometer sua função de abastecimento público.

Dessa forma, é fundamental cuidar das nascentes e dos córregos que compõem a rede hídrica que alimenta o manancial Balneário da Amizade. Assim, a gestão de bacias hidrográficas deve contemplar a preservação e melhoria da água quanto à quantidade e qualidade, para múltiplos usos. Considerando-se que o Artigo 225 da Constituição Federal de 1988 garante o direito ao meio ambiente ecologicamente equilibrado e a noção de bem comum, tendo o Poder Público o dever de defendê-lo e preservá-lo para as presentes e futuras gerações, a adequada gestão das águas torna-se fundamental para a manutenção desses recursos e garantia de reprodução da vida em todas suas formas.

Para Gonçalves (2006), a gestão do meio ambiente no Brasil tem origem via Estado e a legislação ambiental brasileira apresenta-se de forma bem estruturada a fim de conceber a gestão do meio ambiente. Isto também foi possibilitado e expandido com a Constituição Federal de 1988, bem como, no que se refere à água, a partir da Lei 9.433/1997, que definiu a Política Nacional de Recursos Hídricos e criou o Sistema Nacional para o Gerenciamento de Recursos, e da lei estadual no 7.663/1991, que estabeleceu a Política de Recursos Hídricos e o Sistema de 


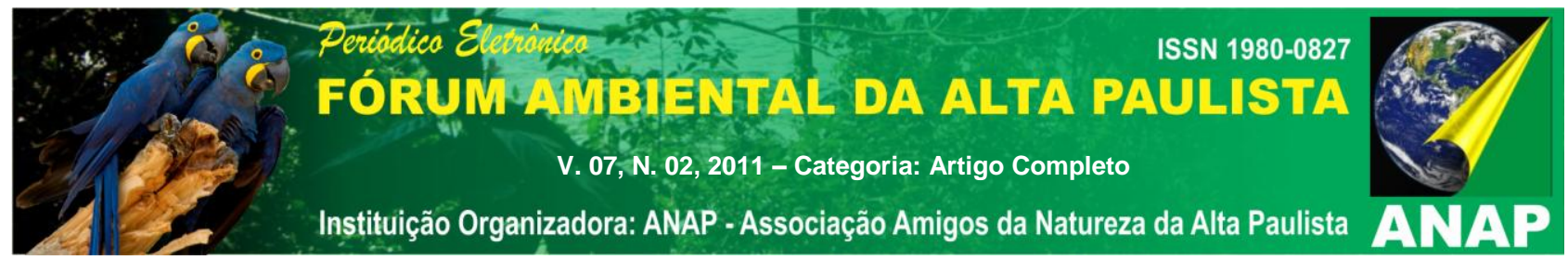

Gerenciamento de Recursos Hídricos do Estado de São Paulo. Essas leis possibilitam a implementação de ações a favor da proteção dos recursos hídricos e controle de seus usos (e abusos) na sociedade.

As leis de águas, anteriormente mencionadas, têm como diretriz a adoção da bacia hidrográfica como unidade físico-territorial de planejamento e gerenciamento. A bacia hidrográfica constitui, segundo Christofoletti (1980), uma área drenada por um determinado rio ou por um sistema fluvial, funcionando como um sistema aberto, em que ocorre a entrada e saída de energia e matéria. E também discute e sugere distinguir os impactos ou efeitos da ação humana nas condições do meio ambiente natural (ecossistemas e geossistemas) e os impactos ou efeitos provocados pelas mudanças do meio ambiente nos estados que envolvem a vida dos seres humanos (CHRISTOFOLETTI, 1993).

Nessa abordagem de Christofoletti, além de sua compreensão integrada, possibilita-se adotar a bacia hidrográfica como unidade de planejamento ambiental e de mobilização social, estimulando que a população local participe dos processos de decisão. Portanto, a adoção da bacia hidrográfica permite o desenvolvimento de um processo de descentralização do planejamento e da gestão das águas, através dos Comitês de Bacias Hidrográficas, com participação social e integração institucional.

Os estudos de bacia hidrográfica permitem abordar e conhecer alguns aspectos da relação estabelecida pela Sociedade com a Natureza, pois se conclui que o cumprimento da legislação tem condições de viabilizar e garantir o uso sustentável dos recursos, especialmente com o funcionamento adequado do sistema de gestão. Para isso é necessário compreender o meio de forma global, justificandose a importância da análise integrada interdisciplinar sobre o meio ambiente.

O planejamento ambiental do território (ou de uma bacia hidrográfica) transforma-se em um elemento tanto básico como complementar para o desenvolvimento econômico e social e para a otimização do plano de uso, manejo e gestão de qualquer unidade territorial (Rodriguez et al, 2004).

Contudo, o objetivo geral desse trabalho de iniciação científica, que se encontra em fase de desenvolvimento, é contribuir para o planejamento ambiental da bacia do Balneário da Amizade, bem como para o gerenciamento de seus recursos hídricos, e assim aprofundar conhecimentos teórico-metodológicos sobre o 


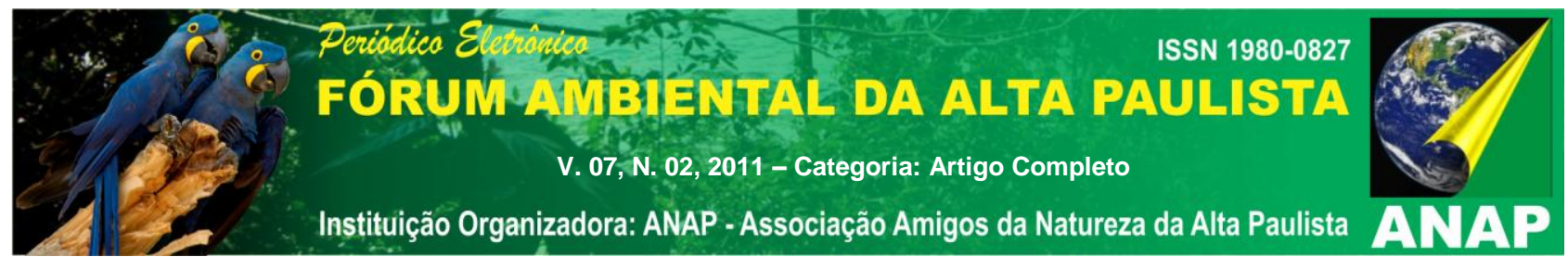

tema. Além de elaborar a fase de inventário da bacia do Balneário da Amizade, incluindo mapas temáticos e de síntese; identificar problemas ambientais e sociais presentes na bacia do Balneário da Amizade; identificar e analisar projetos formulados e as experiências de planejamento e de gestão das águas desenvolvidas na bacia do Balneário da Amizade pelos órgãos públicos municipais e pelo $\mathrm{CBH}$ Pontal do Paranapanema.

\section{2. ÁREA DE ESTUDO}

A escolha da bacia do Balneário da Amizade para o estudo reflete a preocupação com a recuperação ambiental e conservação da área, em especial a represa do Balneário da Amizade, devido sua importância a população local. O mesmo que faz limite dos municípios de Álvares Machado e Presidente Prudente, possui em sua represa artificial um cenário de degradação ambiental e precárias ações políticas, e mesmo não tendo características atribuídas ao seu nome, Balneário, encontram-se pessoas que se utilizam do local, mesmo sem infraestrutura para atividades de lazer e obtendo a qualidade da água de seu manancial comprometida. Também são encontradas locais na bacia utilizados como descartes de resíduos sólidos e resíduos de construção e demolição (RCD).

Nesta perspectiva optou-se por um trabalho de inventário para analisar as características do meio físico e os projetos municipais para área. Já que o balneário é a terceira opção da Companhia de Saneamento Básico do Estado de São Paulo (SAPESP) para a captação e abastecimento de água em Presidente Prudente, em período de seca, a sua importância não se faz apenas ambientalmente, mas também socialmente.

Sobre a bacia estudada nesta pesquisa, Pereira (2010) afirma que os espigões divisores de água de rios afluentes do Rio Paraná, a partir de seus topos a expansão estendeu-se pelas cabeceiras de drenagem (nascentes), vertentes e canais fluviais de primeira ordem, até atingir fundos de vale. Sendo os compartimentos do relevo apropriados e impermeabilizados com edificações e pavimentação das ruas e lotes, aumentou-se substancialmente o volume e velocidade das enxurradas, concentrando, portanto, o escoamento das águas 


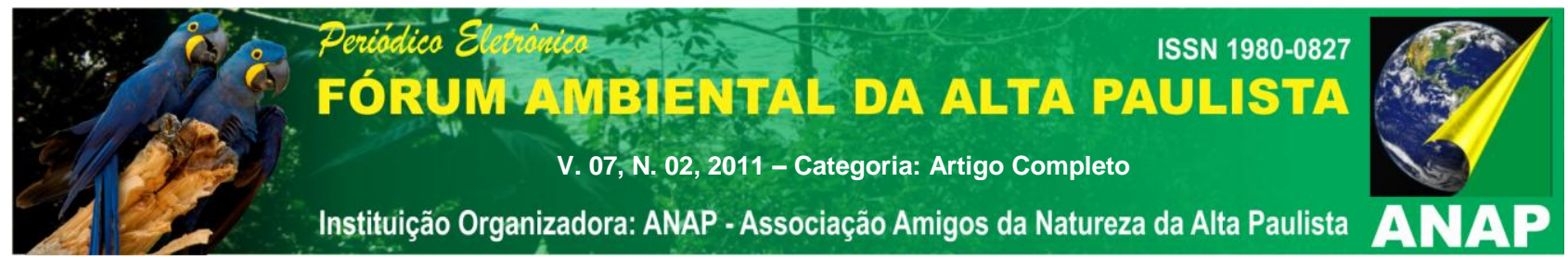

pluviais e acelerando os processos erosivos. Este fato aliado a falta de planejamento adequado, desmatamento de matas ciliares e lançamento indiscriminado de resíduos sólidos e líquidos, viabilizaram a formação de voçorocas de grandes proporções em áreas da periferia urbana a ponto dos desmoronamentos de taludes colocarem em situação de risco moradias e habitantes das proximidades.

A bacia do Balneário da Amizade possui uma área de drenagem de 19,24 $\mathrm{Km}^{2}$, tendo suas coordenadas geográficas: $22^{\circ} 06^{\prime} 26,04^{\prime \prime} \mathrm{S}$ de latitude e $51^{\circ} 26^{\prime} 43,50^{\prime \prime} \mathrm{W}$ de longitude. Está inserida na bacia do alto curso do córrego do Limoeiro, que por sua vez encontra-se na bacia hidrográfica do Rio Santo Anastácio, na divisa dos municípios de Presidente Prudente e Álvares Machado, e na Unidade de Gerenciamento de Recursos Hídricos Pontal do Paranapanema. Os municípios de Presidente Prudente e Álvares Machado pertencem à Microregião Geográfica de Presidente Prudente, no interior do estado de São Paulo (figura 1).

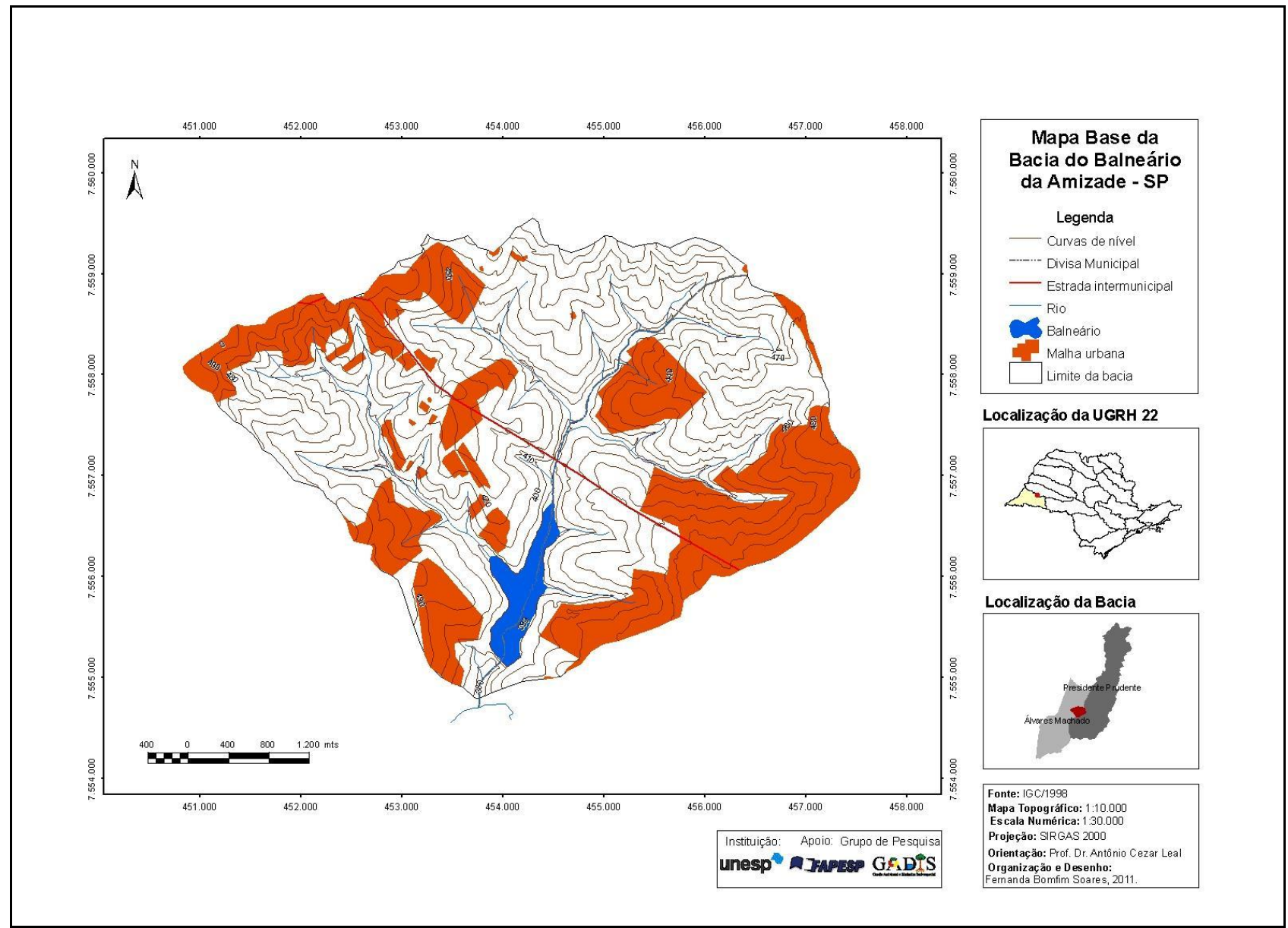

Figura1. Mapa base da bacia do Balneário da Amizade e a sua localização, 2011. 


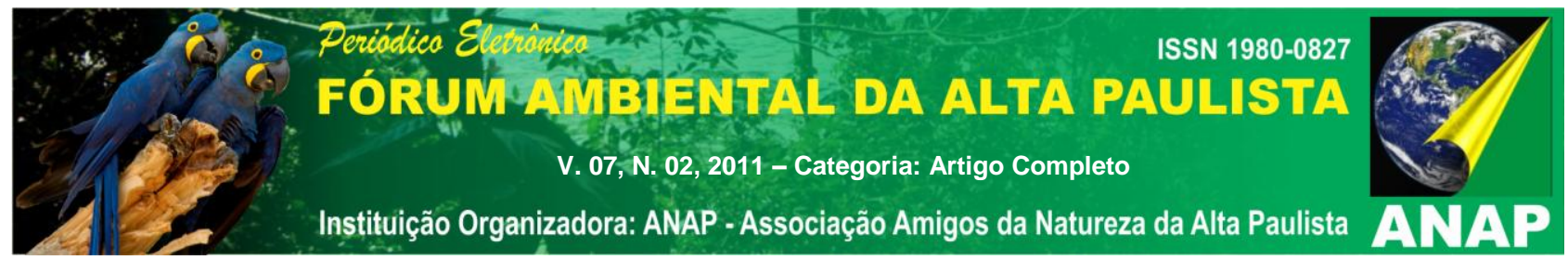

Segundo dados municipais, o reservatório do balneário possui vazão média de 143,l/s e de acordo com sua disponibilidade hídrico o sistema não tem relevância para o município, se prestando para retiradas de baixas vazões por pequenos intervalos de tempo. Entretanto, tem sido usado de forma estratégica, por curtos períodos, em situações raras, como suporte operacional ao abastecimento de água de Presidente Prudente.

A bacia do Balneário da Amizade é atravessada, de leste a oeste, pela Estrada Intermunicipal Arthur Boigues Filho (popularmente conhecida como Estrada da Amizade), que liga os municípios citados, de noroeste a sudoeste pela Rodovia Julio Budiski (SP-501).

Segundo a Secretaria de Planejamento de Presidente Prudente, o Balneário da Amizade, construído em 1978, é uma represa de $379.271 \mathrm{~m}^{2}$ com volume total de 2.066.000 $\mathrm{m}^{3}$, localizado na divisa dos municípios supramencionados, no perímetro urbano e no eixo de expansão urbana das cidades sedes municipais, que estão em processo de conurbação.

Este acordo intermunicipal é citado na lei municipal de Presidente Prudente $\mathrm{n}^{\circ}$ 1.984/1978, que dispõe sobre a autorização para adquirir por doação, com encargos, terras ao redor do balneário. Sob a gestão do prefeito Paulo Constantino (1978-1981) a área do balneário foi um produto de doação com encargos dos proprietários Rosário Calabreta e sua mulher Antonia S. Calabreta. Ao analisar quais foram esses encargos é possível identificar como foi iniciado o processo de urbanização nas proximidades do balneário, como exposto na lei 1.984/78:

PARÁGRAFO ÚNICO: os encargos que oneram a doação são os seguintes:

a) Adiantamento de parte da área correspondente a dez por cento (10\%) reservada ao município, em futuro loteamento nas imediações do Balneário da Amizade;

b) Fornecer maquinários para realizar o arruamento do futuro loteamento (grifo nosso).

Observa-se, então, que a área da bacia do Balneário da Amizade surge sob condição, legitimada por Lei específica, de ser urbanizada após a construção do balneário. 


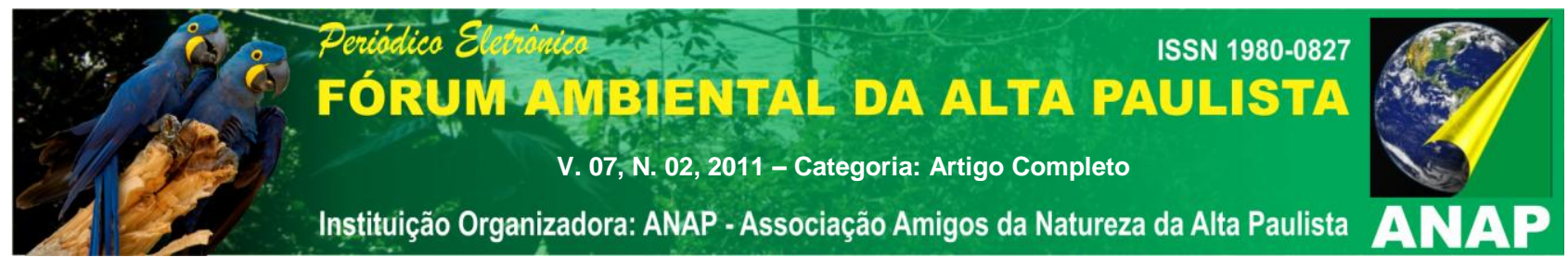

Nos estudos realizados, pode-se verificar que a falta de um planejamento adequado para disciplinar a urbanização da bacia, aliado ao processo de expansão urbana e especulação imobiliária, está causando vários impactos como: ocupações em áreas de preservação e proteção ambiental; serviço ineficiente de infra-estrutura urbana, poluição de suas nascentes, assoreamento do balneário, e outros que ainda serão discutidos paulatinamente nesta pesquisa.

\section{METODOLOGIA}

O planejamento ambiental constitui um dos instrumentos fundamentais para a proteção das águas e para orientar e subsidiar sua gestão, tendo em vista que, a partir das políticas públicas, em especial a política ambiental, o gerenciamento dos recursos hídricos pode representar uma oportunidade para resolução de problemas ambientais e garantia de sustentabilidade do desenvolvimento.

Para Mateo Rodriguez (1994, p.583-584), no planejamento ambiental o objetivo principal da política de sustentabilidade é:

Garantir de forma completa, as condições ecológicas para o desenvolvimento efetivo da produção social, e de todas as atividades da população, através do uso racional e da proteção dos recursos do meio ambiente, articulando-se através de quatro níveis devidamente integrados: a organização ambiental do território; a avaliação ambiental de projetos; a auditoria e peritagem ambiental e a gestão do modelo de Planejamento Ambiental. Grifo do Autor.

Leal (1995) aplica etapas adaptadas da metodologia de Mateo Rodriguez (1994) no Planejamento Ambiental. Essas etapas são dividas em inventário, diagnóstico ambiental, prognóstico e proposta. O inventário:

[...] consiste num levantamento detalhado do ambiente urbano da microbacia, considerando sua localização, o processo histórico de produção desse espaço e seus aspectos naturais e sociais, particularizados e inter-relacionados, de forma a obtermos unidades físicas, unidades de uso e ocupação do solo e unidades ambientais [...]. Também, em uma etapa inicial de aproximação e compreensão da realidade local, e, por isso, torna-se fundamental para a realização de todas as etapas posteriores do Plano Motivador. (LEAL, 1995, p. 47) 


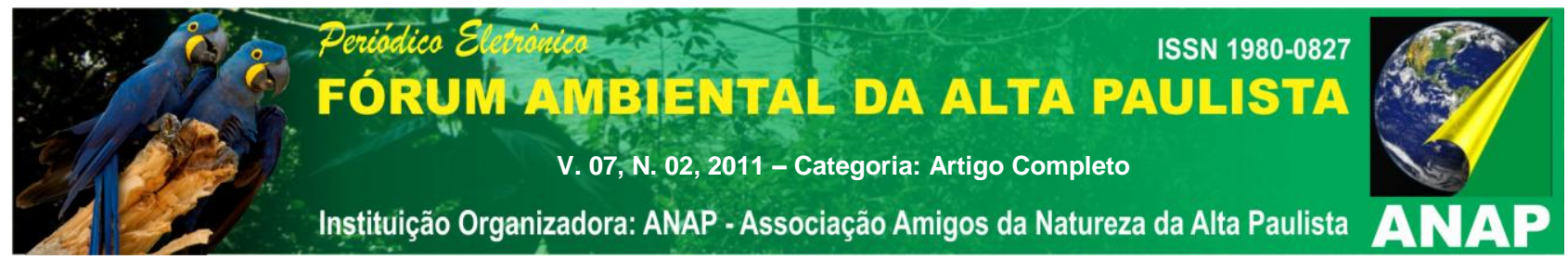

Segundo Santos (2004, p.34), inventário e diagnóstico, de um planejamento ambiental, representam o caminho para compreender as potencialidades e as fragilidades da área de estudo, da evolução histórica de ocupação e das pressões do homem sobre os sistemas naturais. Também esclarecem sobre os acertos e os conflitos do uso da terra e os impactos passados, presentes e futuros. Estas avaliações consideram variações temporais, espaciais e escalares, em um processo de ir e vir, em diversas combinações. Formam-se retratos da área que comparados, somados e interpolados, ressaltam as principais características e fornecem indícios da dinâmica da região. Dependendo da linha metodológica utilizada, podem-se empregar unidades territoriais ou unidades de paisagem, ou zonas ou cenários. Espera-se, na realidade, compartimentar o espaço em unidades de planejamento e gerenciamento. A cada unidade deve corresponder um conjunto específico de alternativas e ações.

No desenvolvimento desta pesquisa adotou-se a proposta metodológica de Rodriguez (1994) e adaptada por Leal (1995), notadamente da etapa do inventário a qual inclui procedimentos como coleta e sistematização de dados e informações, trabalhos de campo, elaboração de mapas temáticos e de síntese, bem como a elaboração de textos, gráficos, quadros e tabelas, os quais serão sistematizados em relatórios científicos. Como exposto na figura 2, abaixo. 

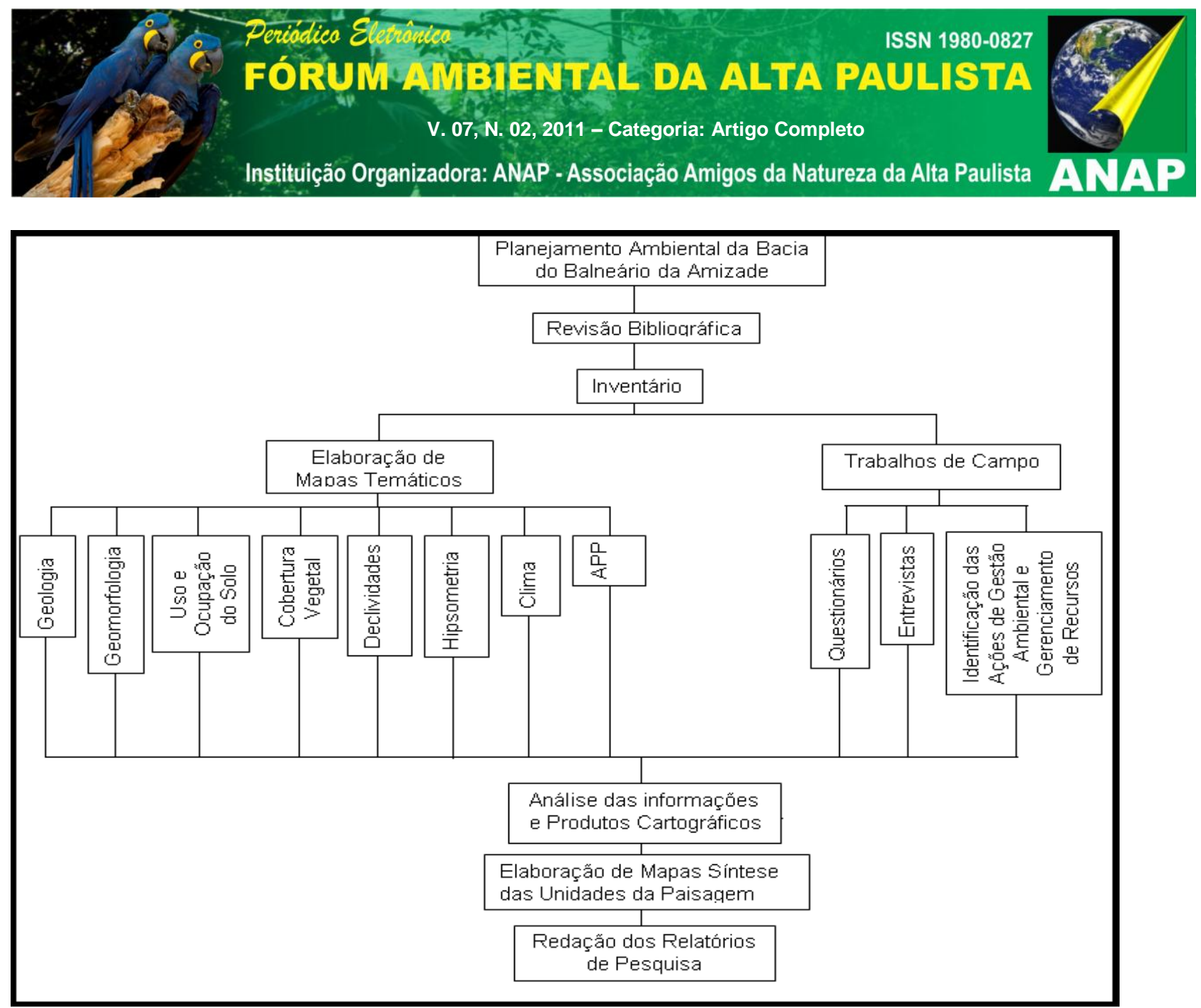

Figura 2. Croqui das atividades do projeto de planejamento ambiental da Bacia do Balneário da Amizade: Metodologia para realização do Inventário.

O Inventário é a fase do levantamento detalhado das informações gerais da bacia hidrográfica, sendo assim, a base para todo o processo de planejamento. Constitui uma etapa de compreensão da realidade local e deve ser entendido como um processo contínuo de avaliação, seja por alterações nos objetivos, seja por diversas dificuldades de obtenção de informações ou impedimentos técnicos de representação cartográfica (LEAL, 1995).

Assim, o inventário contempla a elaboração e compilação de mapas temáticos, trabalhos de campo e elaboração de mapas síntese. Cartas de geologia, geomorfologia e solos foram compiladas na escala 1:50.000, baseadas no mapa geomorfológico elaborado por Ross (1997) e nos mapas disponíveis no planos de bacia e nos relatórios de situação de recursos hídricos do CBH-PP. Os mapas e cartas temáticas foram elaboradas utilizando os softwares ArcGis 9.2 e CorelDraw X3, com licenças disponíveis na UNESP, na escala 1:10:000, com os seguintes temas: Hipsometria; Declividades; Cobertura Vegetal; Uso e Ocupação do solo e das 


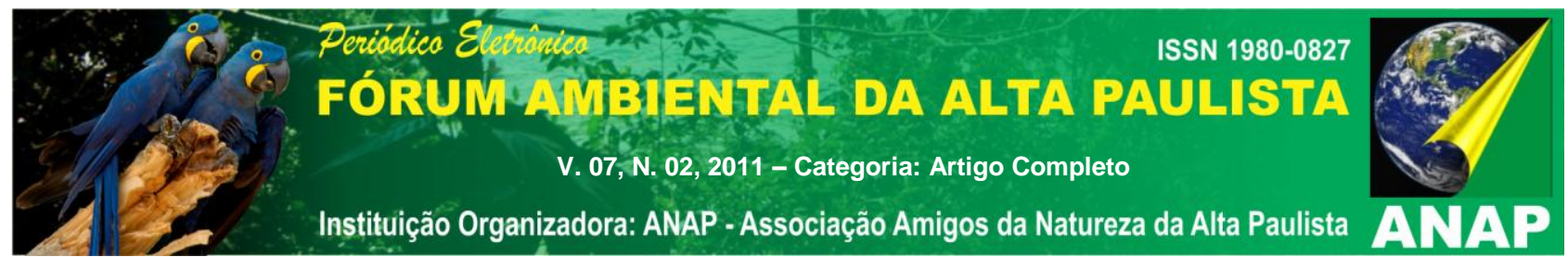

Áreas de Preservação Permanente na bacia do Balneário da Amizade, identificando conflitos entre uso e preservação dessas áreas.

Das atividades desenvolvidas, destacam-se trabalhos de campo para coleta de informações, reconhecimento geral da área e entrevistas com os responsáveis pelos órgãos públicos municipais, para entender qual o objetivos dos projetos públicos municipais de recuperação da área; a elaboração da carta clinográfica representando as declividades do terreno; e a carta hipsométrica.

Nesta etapa preliminar do inventário, após a elaboração do Mapa Base, iniciase a construção da Carta Hipsométrica da bacia do Balneário da Amizade (figura 3). A carta a representa as classes altimétricas da bacia, o agrupamento das 10 classes altimétricas seguiu a eqüidistância entre as isolinhas, sendo esta de 10 metros para a escala cartográfica trabalhada de 1:10.000. Assim temos a classe de cotas mínimas com 370 metros de altitude do nível do mar e chegando a altitude de 490 metros.

A carta hipsométrica é caracterizada por permitir a análise altimétrica da área, proporcionando uma visão ampla da forma do relevo e do rebaixamento do terreno em direção ao córrego do limoeiro ou da bomba.

Então, a carta se propôs ressaltar as definições da Semiótica Cartografia, muito discutido na Geociência, onde as cores devem seguir certo padrão. Observando a carta identifica-se um resultado esteticamente significativo, por causa do acentuado contraste existente entre as cores escolhidas e a altura do relevo. 

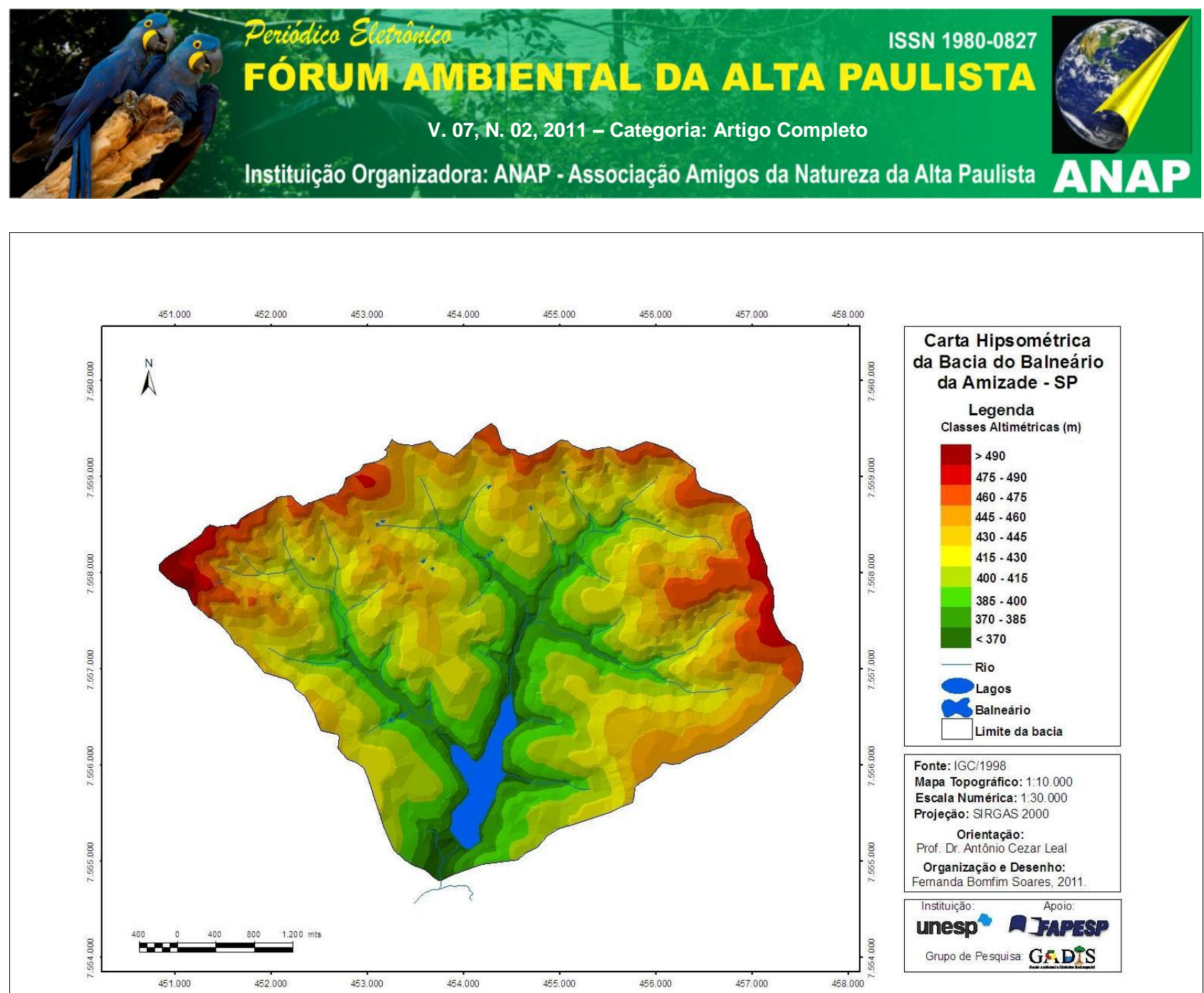

Figura 3. Carta Hipsográfica da Bacia do Balneário da Amizade - SP, 2011.

Já carta clinográfica, representa as declividades ou inclinações de uma região através do distanciamento das curvas de nível, em que para sua confecção utilizouse uma simbologia para cada classe, partindo da mais clara para a mais escura, ou seja, a medida que aumenta a declividade, intensifica-se a tonalidade das cores. Devido o tamanho da área e para uma melhor visualização do leitor, a carta foi divida em 4 classes temáticas, sendo elas: > 20\%; $10-20 \% ; 5-10 \%$; 0 - 5\%.

Essas classes temáticas foram dividas pelo grau de inclinação segunda a metodologia proposta de De Biase (1992). A metodologia tem como critério a confecção de classes de acordo com a percepção do autor da carta. No caso da bacia do Balneário da Amizade o relevo, predominantemente de colinas amplas, permitiu a divisão de classes em intervalos mais curtos, na proximidade com o balneário o relevo obtém a característica de fundo de vale amplo e aberto, com pouca vegetação e muitas áreas de solo exposto. 


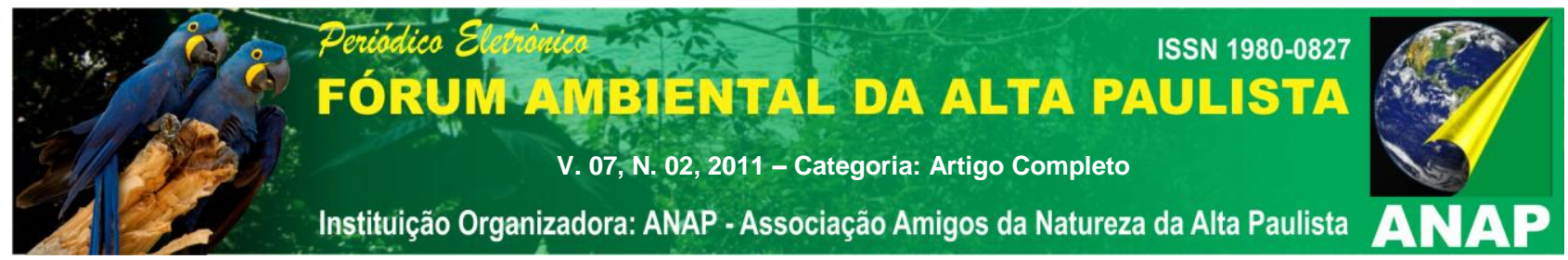

A produção da carta clinográfica serve para analisar e decidir o melhor uso e aproveitamento do solo, uma vez que se torna necessária a compreensão das características físicas ambientais para que se tenha uma melhor adequação dos projetos e os usos referentes ao solo. Essa análise se completará com a elaboração das cartas posteriores, como a Geomorfológica e Geológica, facilitando o conhecimento físico da bacia para indicar as melhores propostas na conclusão do planejamento ambiental.

A declividade do terreno contribui para o escoamento das águas. Quanto maior for o trecho em declive, maior será o escoamento da água pela superfície, arrastando outros materiais para os recursos hídricos superficiais, influenciando assim, a qualidade da água. (MOTA, 1995).

De acordo com De Biase (1970), a carta clinográfica tem sido utilizada de maneira quase obrigatória, nessas duas últimas décadas, em planejamento Regional, Urbano e Agrário, juntamente com outras representações gráficas de variáveis tais como: orientação de vertentes, insolação direta, direção e velocidade de ventos, entre outras, permitindo assim, com suas correlações uma melhor compreensão e um equacionamento dos problemas que ocorrem no espaço analisado.

A definição das classes de declividades para serem utilizadas na confecção da carta clinográfica, atende a um espectro bem amplo no que diz respeito à sua utilização na representação cartográfica, para os mais variados usos e ocupação do espaço, seja ele urbano ou agrícola.

Conforme afirmação de Herz e De Biasi (1989), as classes de declividade podem propor os seguintes limites em porcentagem ou graus, o importante é optar pela melhor visualização, leitura, da carta (HERZ, R. e DE BIASI, M. 1989):

$<-5 \%$ - Limite urbano - industrial, utilizados internacionalmente, bem com em trabalhos de planejamento urbano efetuados pelo Instituto de Pesquisas Tecnológicas do Estado de São Paulo e da EMPLASA - Empresa Metropolitana de Planejamento da Grande São Paulo S. A.

5 - 12\% - Este limite possui algumas variações quanto ao máximo a ser estabelecido (12\%), pois alguns adotam as cifras de $10 \%$ e / ou $13 \%$. A diferença é muito pequena, pois esta faixa define o limite 


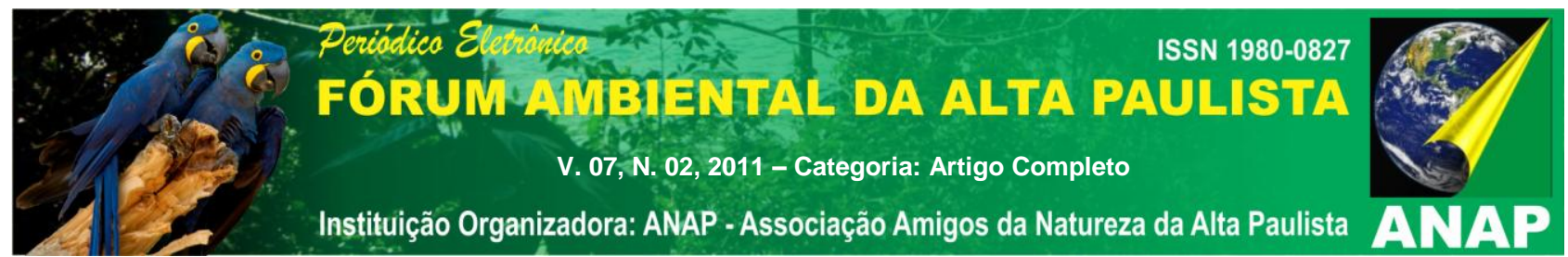

máximo do emprego da mecanização na agricultura. (CHIARINI e DONZELLI, 1973).

12 - 30\% - O limite de 30\% é definido por legislação federal - Lei 6766/79 - também chamada de Lei Lehmann, que vai definir o limite máximo para urbanização sem restrições, a partir do qual toda e qualquer forma de parcelamento far-se-á através de exigências específicas.

30 - 47\% - O Código Florestal, fixa o limite de 25 (47\%), como limite de corte raso, a partir do qual a exploração só será permitida se sustentada por cobertura de florestas. Lei N. 0 4771/65 de 15/09/65.

$>47 \%$ - O artigo 10 do Código Florestal prevê que na faixa situada entre $25^{\circ}(47 \%)$ a $45^{\circ}$ (100\%), "não é permitida a derrubada de florestas, ...só sendo tolerada a extração de toros, quando em regime de utilização racional, que vise a rendimentos permanentes".

Dibieso (2007) afirma que as classes de declividades podem ser estabelecidas através de critérios como:

$<5 \%$ : áreas planas, adequadas ao uso e ocupação do solo (no caso de vertentes e/ou topos) ou inadequadas (no caso de planícies fluviais, pelo risco de inundação e por estarem em área de preservação e proteção ambiental);

5 a 10\%: área com moderada suscetibilidade à erosão, com poucas restrições ao uso e ocupação do solo;

10 a 20\%: área com forte suscetibilidade à erosão, necessitando de adequado manejo para sua utilização;

$\geq 20 \%$ : áreas com escoamento superficial muito rápido e muito forte suscetibilidade à erosão. (DIBIESO, 2007 p.55)

A mesma interpretação de classes utilizada por Dibieso (2007) e De Biase (1989) foi colocada em prática nesse trabalho, porém devido ao tamanho da área a adoção das classes de declividades foi realizada em porcentagem, mas com quatro classes para facilitar a visualização e leitura da carta clinográfica.

Identificamos, na carta a seguir, que as áreas maiores de $20 \%$ de declividade estão presentes nas margens dos canais fluviais, próximas a pequenos lagos e nascentes, e a jusante da represa do balneário sendo áreas que estão sujeitas a inundação e segundo o artigo 10 do Código Florestal corresponde à área de preservação permanente (APP).

A declividade de 10\% - 20\% estão em áreas ao leste e oeste da bacia, onde há concentração da malha urbana, e é onde mais encontramos solos em processo de erosão, pois são áreas com escoamento superficial muito rápido. Para essa área a lei $n^{\circ} 4771 / 65$ do Código Florestal indica que a exploração da área só será 


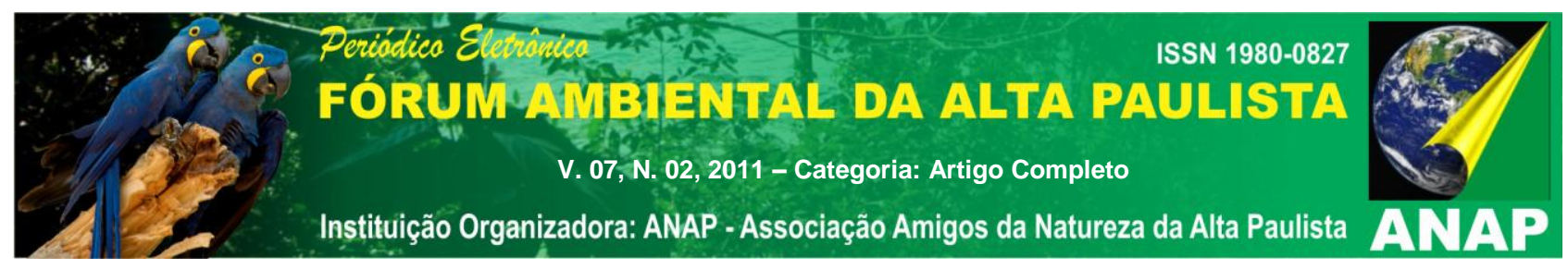

permitida se sustentada por cobertura de florestas, porém essa não é a realidade encontrada na área.

Já a declividade de 5\% - 10\%, presentes em vários locais da bacia, caracteriza-se em áreas com poucas restrições ao uso e ocupação do solo. Assim obtém nessa área pequenos focos de erosão, devido a sua declividade moderada e ao uso desse solo, que em campo, podemos identificar esse uso como: agricultura familiar, pastagem, plantio de eucalipto e malha urbana. Ao leste do Balneário da Amizade esse grau de declividade caracteriza uma área suscetível a urbanização, porém a proximidade do balneário não a torna ideal.

Entretanto nos intervalos de $0-5 \%$ de declividade localizam-se em áreas pouco urbanizadas, a leste e oeste da represa do Balneário da Amizade. De acordo com Dibieso (2007) podemos caracterizar essa área como adequada ao uso e ocupação do solo, devido à sua característica plana, porém ao leste da represa do balneário e em toda a área que margeia o fluxo d'água principal, o córrego do limoeiro ou da bomba, há áreas inadequadas por causa de uma planície fluvial que ocasiona um risco de inundação. Portanto esse intervalo de declividade merece atenção especial por se apresentarem área de preservação e proteção ambiental. 

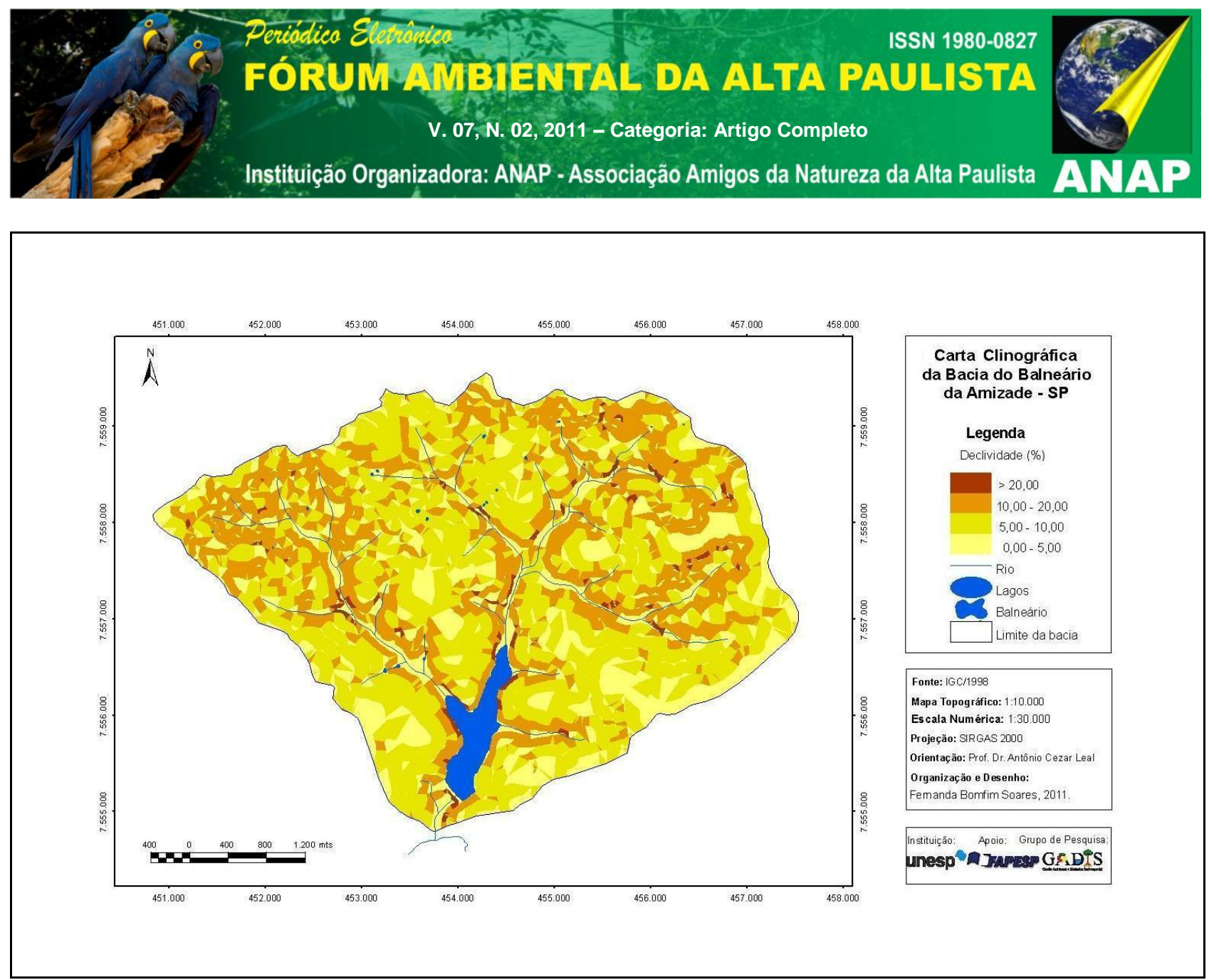

Figura 4. Carta Clinográfica da bacia do Balneário da Amizade - SP, 2011.

Outra proposta desta pesquisa é a análise dos projetos públicos municipais de Presidente Prudente e Álvares Machado, ambos os projetos com investimentos de órgãos competentes como o FEHIDRO e do Governo Federal, através do Ministério de Turismo, com o programa: Turismo Social no Brasil. Os trabalhos em campo e as cartas já confeccionadas auxiliam o trabalho de análise e diagnóstico das propostas municipais para a recuperação e revitalização da área.

\section{RESULTADOS E DISCUSSÃO}

O uso e ocupação do solo na bacia do Balneário da Amizade se diferenciam nos municípios onde se localiza, ou seja, em Presidente Prudente o uso desse solo é predominantemente urbano, já em Álvares Machado, município sem grandes processos de expansão urbana, prevalecem áreas agrícolas e de pastagem. Esse uso inadequado do solo se reflete em acentuados impactos ambientais, como a baixa qualidade da água, grande quantidade de matéria orgânica nos cursos d'água 


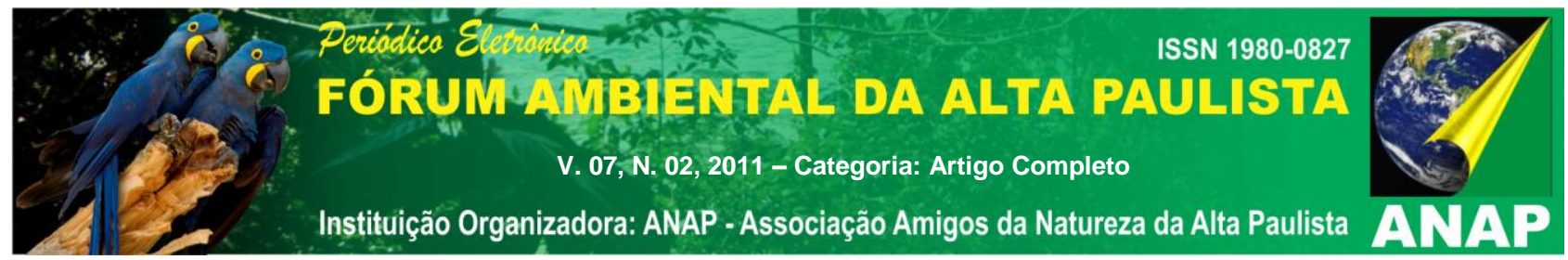

(decorrentes de esgotos clandestinos), erosão do solo, ausência de áreas de preservação permanente, de mata ciliar e fauna local.

Assim como se diferencia o uso do solo nos dois municípios, os projetos públicos de recuperação da área também objetivam ações distintas devido a diferentes gestões públicas.

O projeto de Revitalização do Balneário da Amizade da Secretaria de Meio Ambiente de Presidente Prudente o objetivo deste é revitalizar o balneário através de obras de engenharia civil, agronômica que possibilitem a completa urbanização do local dando condições para a utilização desse recurso hídrico para recreação e lazer dos munícipes de Presidente Prudente e Álvares Machado como ocorreu na década de 80 , sendo da mesma forma uma contribuição na recuperação ambiental da Bacia do Alto Limoeiro.

Já o projeto de Recuperação Ambiental proposto por Álvares Machado, financiado pelo FEHIDRO com o apoio técnico do Comitê de Bacia Hidrográfica do Pontal do Paranapamena ( $\mathrm{CBH}$ - PP), objetiva contribuir na recuperação ambiental da Bacia do Alto Limoeiro, pela demarcação, pelo isolamento e pelo reflorestamento das Áreas de Preservação Permanentes e minimizar o assoreamento dos corpos d'água, prevenindo e controlando os processos erosivos através de práticas agronômicas. Especificamente o projeto propõe delimitar as Áreas de Preservação Permanente com a implantação, através de cercas, os limites de exploração da terra na bacia de contribuição do manancial, impedindo a entrada de pessoas e de animais domésticos herbívoros de grande porte nas demais APPs, permitindo a preservação e facilitando a fiscalização do uso destas áreas. Sobre as práticas agronômicas de recuperação ambiental, almeja recompor as matas ciliares no lago e em todos os corpos d'água, inclusive nas nascentes, permitindo a interligação das matas remanescentes, propiciando a formação de corredores naturais, evitando o confinamento de espécies, e promover o enriquecimento florestal como indutor e acelerador da sucessão ecológica, como corretor das características gênicas indesejáveis e conferidor de estabilidade a comunidade formadora do ecossistema.

Mesmo com esses grandes projetos de recuperação há a necessidade de ações que integrem a recuperação ambiental da área e a infra-estrutura urbana, por parte das prefeituras, principalmente a do município de Álvares Machado que iniciou 


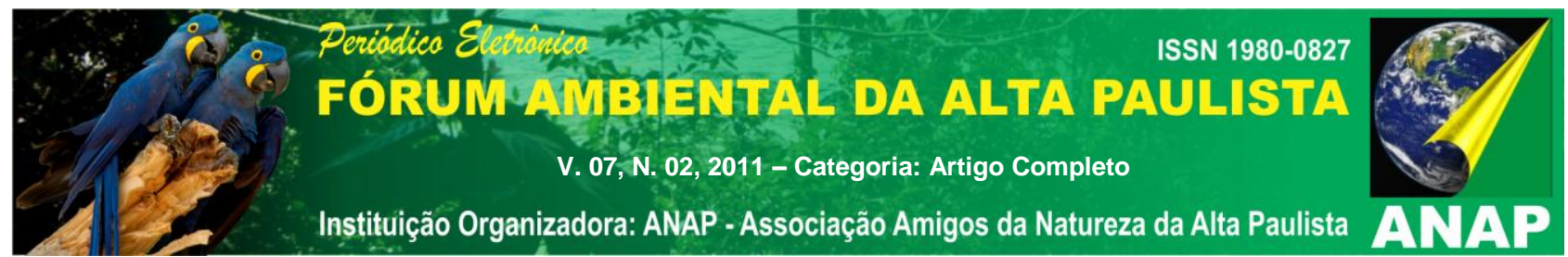

seu projeto de reflorestamento, mas que não atende as necessidades atuais de seus moradores, tais como asfalto e melhorias de vias públicas, iluminação pública e limpeza e retirada de entulhos de locais próximos as nascentes da Bacia do Balneário.

Portanto, os diferentes projetos públicos para a mesma área dificultam as ações de recuperação da bacia do Balneário da Amizade. Enquanto Álvares Machado objetiva para área da bacia práticas agronômicas para a recuperação ambiental, Presidente Prudente intensifica seus projetos e obras para urbanização da área com a abertura de novos lotes urbanos e área de lazer para a população. É importante destacar que os dois projetos incluem a delimitação de áreas de preservação permanente, porém os dois projetos já iniciaram suas obras não respeitando a delimitação exigida pela Legislação Ambiental e descrita em seus projetos (cinquenta metros de APP no entorno da represa do Balneário e em suas nascentes).

\section{REFERÊNCIAS}

AB'SABeR, A., PlANTENBERG, C. (Orgs) Previsão de Impactos. São Paulo: EDUSP, 1995.

ALMEIDA, Josimar Ribeiro de [et al]. Planejamento Ambiental. Caminho para participação popular e gestão ambiental para nosso futuro comum: uma necessidade, um desafio. 2 ed. - Rio de Janeiro: Thex Ed.: Biblioteca Estácio de Sá, 1999.

ÁlVARES MACHADO, PREFEITURA MUNICIPAL. Plano diretor do município de Álvares Machado - SP. Documento cedido em novembro de 2010.

ÁLVARES MACHADO. Lei no 2467/06 (dispõe sobre o Plano diretor da cidade de Álvares Machado). Disponível em: < http://www.alvaresmachado.sp.gov.br>, acesso em 01 de março de 2011.

BRASIL. Instituto Brasileiro de Geografia e Estatítica (IBGE). Cidades@: banco de dados: Disponível em: < http://www.ibge.gov.br>. Acesso em: junho de 2011.

CHRISTOFOLETTI, A. Geomorfologia. São Paulo: Edgard Blucher, 2ed. 1980.

Análise morfométrica das Bacias Hidrográficas. Not. Geomorfol, v.9, n18, 1969. CLAUDINO-SALES. Geografia, Sistemas e Análise Ambiental: abordagem crítica. In: GEOUSP. Espaço e Tempo, São Paulo, № 16, 2004.

DE BIASE, M. Cartas de declividade: confecção e utilização. Geomorfologia, ํo 21, Instituto de Geografia - USP, São Paulo, 1970. 


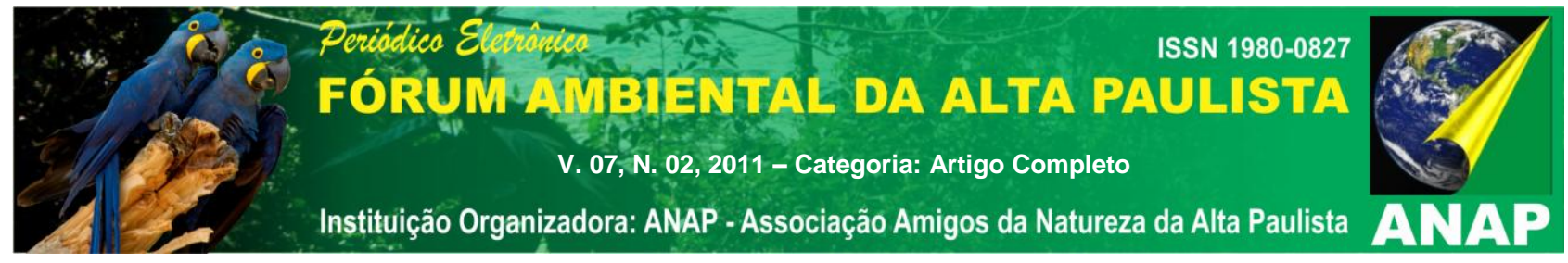

DIBIESO, E. P. Planejamento Ambiental da Bacia Hidrográfica do Córrego do Cedro - Presidente Prudente/SP. Dissertação de Mestrado. Universidade Estadual Paulista, Faculdade de Ciências e Tecnologia, 2006.

HISSA, C. E. V. Geografia e planejamento: entre o puro e o aplicado. Geonomos. Belo Horizonte: v. 6, n. 2, p. 33-43, 1998.

LANNA, A.E.L. Gestão de recursos hídricos. In: TUCCI, C.E.M. (Org.). Hidrologia: ciência e aplicação. Porto Alegre: Ed. da Universidade: ABRH: EDUSP, 1997.

LEAL, A.C. Gestão das Águas no Pontal do Paranapanema - São Paulo. Campinas, 2000. Tese (Doutorado em Geociências - Área de concentração em Administração e Política de Recursos Minerais) - Inst. de Geociências - UNICAMP, 299p.

Meio ambiente e urbanização na microbacia do Areia Branca Campinas - São Paulo. Rio Claro, 1995. 155p. Dissertação (Mestrado em Geociências e Meio Ambiente) - Instituto de Geociências e Ciências Exatas, Universidade Estadual Paulista.

PRESIDENTE PRUDENTE, Prefeitura Municipal. Plano Diretor do Município de Presidente Prudente - SP. Cedido pelo secretário do Meio Ambiente, em fevereiro de 2011.

. Lei Complementar no 151/2008 (dispõe sobre o Plano diretor da cidade de Presidente Prudente. Disponível em: <http://www.presidenteprudente.sp.gov.br>. Acesso em março de 2011.

Projeto de Revitalização do Balneário da Amizade. Disponível em: <http://www.presidenteprudente.sp.gov.br>, acesso em $03 \mathrm{de}$ fev. de 2011.

RODRIGUEZ, M. M. Planejamento Ambiental como campo de ação da Geografia. In: CONGRESSO BRASILEIRO DE GEÓGRAFOS, 5, 1994, Curitiba/PR. Anais. Curitiba: AGB, 1994. v.1, p.582-94.

RODRIGUEZ, J. M. M., SILVA. La Geoecologia del Paiseje, como fundamento para el analisis ambiental. Revista Eletrônica do Prodema, Fortaleza, v.1, n.1, 9. 77- 98, 2007.

RODRIGUEZ, J. M. M., SILVA, E.V. da, CAVALCANTI, A.P.B. Geoecologias das Paisagens: uma visão geossistêmica da análise ambiental. Fortaleza: Editora. UFC, 2007.

MOTA, Suetônio. Preservação e conservação de recursos hídricos. 2. Ed. Rio de Janeiro: ABES, 1995.

PEREIRA, Denise M. Planejamento Ambiental das Nascentes do Córrego dos Macacos - Município de Álvares Machado/SP. Anais do XVI ENG - Encontro Nacional dos Geógrafos. Porto Alegre - RS, 2010.

ROSS, Jurandyr L. S. Geomorfologia: Ambiente e Planejamento. $3^{\circ}$ Ed. São Paulo: Contexto, 1996.

SANTOS, Rosely Ferreira dos. Planejamento Ambiental: teoria e prática. São Paulo - Oficina de Textos, 2004.

SETTI, A.A. Introdução ao gerenciamento de recursos hídricos. Brasília: Agência Nacional de Energia Elétrica e Agência Nacional de Águas, 2001.

SIRGRH - Sistema de Informações para o Gerenciamento de Recursos Hídricos do Estado de São Paulo. Gerenciamento de Recursos Hídricos. Disponível em: 


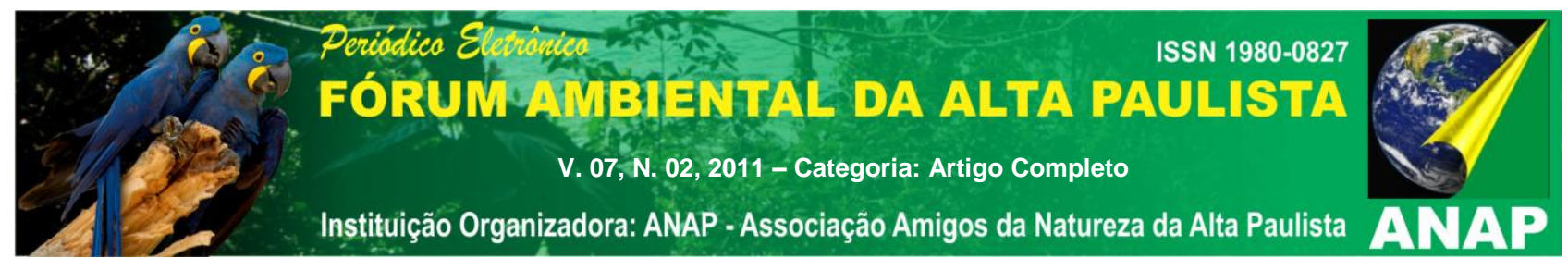

<http://www.sigrh.sp.gov.br/cgi-bin/sigrh_carrega.exe?f=/index/index.html>, acesso em maio de 2011.

SOUZA, M. L; RODRIGUES, G. B. Planejamento urbano e ativismos sociais. São Paulo: UNESP, 2004.

TAKENAKA, E. M. M. Políticas públicas de gerenciamento integrado de resíduos sólidos urbanos no município de Presidente Prudente-SP. Tese (doutorado) - Universidade Estadual Paulista, Faculdade de Ciências e Tecnologia, 2008.

TUNDISI, J. G. Água no século XXI: enfrentando a escassez. São Carlos: RIMA, IIE, 2003. 